Original article

\title{
Use of Quintile Regression to Find Factors Influencing CD4 Cell Count in Iranian Newly Recognized HIV-Infected People (1987-2016)
}

\author{
Maryam Farhadian $^{\mathrm{a}}$, Younes Mohammadi ${ }^{\mathrm{b}}$, Nasrin Shirmohammadi-Khorram ${ }^{\mathrm{c}}$, \\ Mohammad Mirzaei ${ }^{\text {d, }}$ \\ ${ }^{a}$ Research Center for Health Sciences, Department of Biostatistics, School of Public Health, Hamadan University of Medical Sciences, Hamadan, Iran \\ ${ }^{\mathrm{b}}$ Modeling of Noncommunicable Diseases Research Center, Department of Epidemiology, School of Public Health, Hamadan University of Medical Sciences, Hamadan, \\ Iran \\ ${ }^{\mathrm{c}}$ Department of Biostatistics, School of Public Health, Hamadan University of Medical Sciences, Hamadan, Iran \\ ${ }^{\mathrm{d}}$ Hamadan Health Center, Hamadan University of Medical Sciences, Hamadan, Iran
}

\section{A R T I C L E I N F O}

\section{Keywords:}

CD4 count

HIV

Quintile count regression

Iran

\begin{abstract}
A B S T R A C T
Background: The number of CD4 cell counts is one of the markers that are widely used to assess the level of disease progression. Potential risk factors may have a different relationship at different points in the CD4 distribution. For example, some factors may have a weak link with the CD4 mean. While their relationship at the lower levels of CD4 is very strong. Understanding such a different relationship to identify a population at risk based on different levels of CD4 is very beneficial. Accordingly, this study aimed to use quantile regression to provides a more comprehensive analysis of the factors associated across different quantiles of CD4 counts at the time of diagnosis in Iranian newly recognized HIV-infected people.

Methods: This retrospective cohort study included $4402 \mathrm{HIV}$-infected patients from 31 provinces of Iran from 1987 to 2016. Patients' information included baseline CD4 cell count, age, sex, marital status, educational level, job status, way of HIV transmission, year of diagnosis, TB co-infected, clinical stage at the time of diagnosis. Quantile regression models were fitted to the data.

Results: The study findings indicated that variables, such as older age, clinical stage, transmission way, and year of HIV diagnosis could play the role of risk factors for CD4 counts at the time of diagnosis in HIV patients. However, the relationship between different variables was not uniformly distributed in many different quantiles. Conclusions: The results of this study will be helpful for public health policymakers to adopt targeted policies aimed at improving the survival of these patients.
\end{abstract}

\section{Introduction}

CD4 (cluster of differentiation 4) cell counts can be used as surrogate markers to estimate the extent of damage to the immune system in AIDS patients. The number of these cells decreases a few weeks after HIV infection and then increases again in the following months but does not reach their initial level before infection. ${ }^{1}$ CD4 cell counting is a tool to measure the number of CD4 cells in the blood. ${ }^{2} \mathrm{~A} C D 4$ cell count is used to monitor the progress of AIDS and to assess the health of the immune system, and the greater the number of cells, the greater the immune system's health. ${ }^{3}$ Due to a variety of environmental, immunological, demographic, and genetic factors, CD4 cell counts vary between healthy individuals and between patients. ${ }^{1,3-5}$ Factors that lead to CD4 cell changes in AIDS patients are complex and multiple. ${ }^{6}$ For AIDS patients to live longer information should be provided on factors that alter the CD4 cell count in the early stages of their disease. ${ }^{5}$

One of the most important predictors of HIV disease progression and AIDS (acquired immune deficiency syndrome)-related mortality is the count of CD4 lymphocytes in HIV-infected people. The increased risk of opportunistic infections and HIV-related malignancies is the consequence of the loss of CD4 cells. To determine the onset of a highly active antiretroviral therapy (HAART), CD4 counting, along with HIV viral load and clinical symptoms, are used. ${ }^{3}$

A low number of CD4 counts is associated with a higher risk for

\footnotetext{
* Corresponding author. Hamadan Health Center, Hamadan University of Medical Sciences, Hamadan, P.O. Box 4171-65175, Iran.

E-mail addresses: maryam_farhadian80@yahoo.com (M. Farhadian), yonesmohammadi@gmail.com (Y. Mohammadi), n.shirmohamadi.kh@gmail.com (N. Shirmohammadi-Khorram), mirzaei3589@gmail.com (M. Mirzaei).
} 
opportunistic HIV infections, which can lead to advanced disease and death. ${ }^{7}$

However, in addition to HIV, there are other factors such as age that can affect the number of CD4 cells. For example, reducing the CD4 response to ART in older people is more predictable. ${ }^{8}$

Identifying factors affecting the level of CD4 apart from ART helps health professionals and patients to help manage and monitor healthcare interventions in people with HIV. Therefore, modeling and analyzing the factors affecting the number of CD4 cells in AIDS research is more and more important. In this case, one of the special problems to be considered is that on average, the effect of covariates on age, sex, education level, and other factors on the number of CD4 cells is studied. $3,5,9,10$

It should be noted that potential risk factors may have a different relationship at different points of CD4 distribution. For example, some factors may have a weak link with the CD4 mean, while their relationship at the lower levels of CD4 is very strong. Understanding such a different relationship to identify a population at risk based on different levels of CD4 is very beneficial. ${ }^{8}$ Accordingly, the use of regression methods such as quantile regressions, in comparison with other regression models based on the mean response, provides a more comprehensive analysis of the factors associated with CD4 cell counting. Therefore, this study aims to use quantile regression to identify and estimate the socio-demographic factors influencing the CD4 cell count at the time of HIV diagnosis in patients followed by a Behavioral Diseases Counseling Centers (BDCC) from 31 provinces of Iran from 1987 to 2016.

\section{Materials and methods}

\subsection{Study design}

In this retrospective cohort study, information on the number of CD4 cells and risk factors associated with HIV patients was extracted from 158 behavioral disease counseling centers (BDCCs) from 31 provinces in Iran from 1987 to $2016 .{ }^{11}$

The quantile regression model was applied to determine the effect of different variables on CD4 counts at diagnosis and different levels of the CD4 distribution. The CD4 cells count measured up to 3 months later at the time of HIV diagnosis was considered as the response variable and the demographic and clinical variables such as age at the diagnosis time, gender, and the date of HIV diagnosis, the mode of HIV transmission, level of education, employment status and TB co-infection was considered as the predictor variables. The coefficients were estimated for each 5 percentile from 5 th to 95 th quantile of CD4 count. Standard errors and 95\% confidence intervals (CI) were estimated using bootstrapping with 1000 replications. The coefficients corresponding to each quantile were plotted along with their 95\% CI. R software was used for statistical calculations.

\subsection{Statistical analysis}

\subsubsection{Quantile regression for count data}

In the simple linear regression model, it is supposed that $\varepsilon_{i}$ s have normal distributions with zero mean and unknown variance $\sigma^{2}$ are independent. $^{12}$

$y_{i}=\beta_{0}+\beta_{1} x_{i}+\varepsilon_{i}$

Due to the assumption of the mean zero, the function of $\beta_{0}+\beta_{1} x_{i}$ is fitted to data with a conditional mean $(E(y \mid x))$ corresponding to the mean in the population of $y$ values with a constant value of the independent variable $\mathrm{x}$. The quantile regression model corresponding to the linear regression model can be shown as follows [13]:
Table 1

Demographic and clinical characteristics of newly diagnosed HIV-infected people in Iran (1987-2016).

\begin{tabular}{|c|c|c|c|c|c|}
\hline Variable & $\mathrm{N}(\%)$ & Mean & $\begin{array}{l}\text { 1st } \\
\text { Quintile }\end{array}$ & Median & $\begin{array}{l}\text { 3rd } \\
\text { Quintile }\end{array}$ \\
\hline All & $\begin{array}{l}4402 \\
(100)\end{array}$ & 344.77 & 113.00 & 288.50 & 506.00 \\
\hline \multicolumn{6}{|l|}{ Age (year) } \\
\hline$<30$ & $\begin{array}{l}1445 \\
(32.8)\end{array}$ & 449.08 & 213.00 & 410.00 & 628.00 \\
\hline $30-40$ & $\begin{array}{l}1856 \\
(42.2)\end{array}$ & 308.03 & 104.00 & 258.00 & 449.75 \\
\hline $40-50$ & $\begin{array}{l}784 \\
(17.8)\end{array}$ & 281.10 & 82.25 & 203.50 & 392.75 \\
\hline $\begin{array}{l}>50 \\
\text { Sex }\end{array}$ & $317(7.2)$ & 241.88 & 72.00 & 172.00 & 334.50 \\
\hline Male & $\begin{array}{l}1372 \\
(31.2)\end{array}$ & 388.65 & 154.25 & 343.00 & 549.75 \\
\hline Female & $\begin{array}{l}3030 \\
(68.8)\end{array}$ & 324.90 & 98.00 & 262.00 & 478.00 \\
\hline \multicolumn{6}{|l|}{ Marital Status } \\
\hline Single & $\begin{array}{l}1429 \\
(32.5)\end{array}$ & 368.82 & 120.50 & 321.00 & 540.00 \\
\hline Married & $\begin{array}{l}2133 \\
(48.5)\end{array}$ & 337.22 & 119.50 & 284.00 & 492.00 \\
\hline Widow & $265(6)$ & 307.27 & 79.00 & 238.00 & 452.00 \\
\hline Divorce & $\begin{array}{l}508 \\
(11.5)\end{array}$ & 333.14 & 96.75 & 252.50 & 505.50 \\
\hline $\begin{array}{l}\text { Unknown } \\
\text { Education }\end{array}$ & $67(1.5)$ & 308.63 & 52.00 & 208.00 & 405.00 \\
\hline Illiterate & $319(7.2)$ & 330.55 & 105.00 & 250.00 & 469.00 \\
\hline Primary School & $\begin{array}{l}1020 \\
(23.2)\end{array}$ & 334.22 & 108.00 & 271.00 & 497.75 \\
\hline Secondary School & $\begin{array}{l}1261 \\
(28.6)\end{array}$ & 346.34 & 123.00 & 300.00 & 502.50 \\
\hline High School & $\begin{array}{l}919 \\
(20.9)\end{array}$ & 358.21 & 114.00 & 302.00 & 530.00 \\
\hline Academic & $274(6.2)$ & 344.16 & 141.50 & 324.50 & 494.50 \\
\hline Unknown & $\begin{array}{l}609 \\
(13.8)\end{array}$ & 346.64 & 95.00 & 285.00 & 495.50 \\
\hline \multicolumn{6}{|l|}{ Job } \\
\hline Employed & $\begin{array}{l}1521 \\
(34.6)\end{array}$ & 345.21 & 104.50 & 292.00 & 509.00 \\
\hline Unemployed & $\begin{array}{l}1740 \\
(39.5)\end{array}$ & 347.36 & 117.00 & 285.00 & 511.00 \\
\hline Unknown & $\begin{array}{l}1141 \\
(25.9)\end{array}$ & 340.24 & 115.00 & 290.00 & 492.50 \\
\hline \multicolumn{6}{|c|}{ Transmission Way } \\
\hline $\begin{array}{l}\text { Injecting drug } \\
\text { users }\end{array}$ & $\begin{array}{l}2104 \\
(47.8)\end{array}$ & 324.54 & 105.00 & 261.00 & 477.00 \\
\hline Unsafe sexual & $\begin{array}{l}1646 \\
(37.4)\end{array}$ & 370.39 & 143.75 & 329.00 & 527.00 \\
\hline Mother to child & $122(2.8)$ & 618.61 & 282.50 & 589.50 & 897.00 \\
\hline Blood transfusion & $14(0.3)$ & 309.71 & 62.50 & 116.00 & 706.25 \\
\hline Unknown & $\begin{array}{l}516 \\
(11.7)\end{array}$ & 281.70 & 75.50 & 213.50 & 427.50 \\
\hline \multicolumn{6}{|c|}{ WHO Clinical Stage } \\
\hline Stage 1 & $\begin{array}{l}1997 \\
(45.4)\end{array}$ & 420.55 & 210.00 & 381.00 & 575.00 \\
\hline Stage 2 & $\begin{array}{l}594 \\
(13.5)\end{array}$ & 333.39 & 123.00 & 276.00 & 454.25 \\
\hline Stage 3 & $\begin{array}{l}575 \\
(13.1)\end{array}$ & 181.67 & 48.00 & 114.00 & 250.00 \\
\hline Stage 4 & $372(8.5)$ & 157.14 & 36.00 & 86.50 & 200.75 \\
\hline Unknown & $\begin{array}{l}846 \\
(19.6)\end{array}$ & 366.77 & 124.50 & 317.50 & 549.50 \\
\hline \multicolumn{6}{|c|}{ Year of HIV Diagnosis } \\
\hline Before 2006 & $530(12)$ & 432.85 & 212.75 & 389.50 & 622.00 \\
\hline $2006-2011$ & $\begin{array}{l}1388 \\
(31.5)\end{array}$ & 325.31 & 105.00 & 268.00 & 465.50 \\
\hline After 2011 & $\begin{array}{l}2484 \\
(56.5)\end{array}$ & 336.85 & 103.00 & 276.50 & 499.75 \\
\hline \multicolumn{6}{|l|}{ TB co-infection } \\
\hline No & $\begin{array}{l}4142 \\
(94.1)\end{array}$ & 350.03 & 118.00 & 299.00 & 510.00 \\
\hline Yes & $260(5.9)$ & 260.91 & 68.25 & 175.00 & 379.00 \\
\hline
\end{tabular}

$y_{i}=\beta_{0}^{p}+\beta_{1}^{p} x_{i}+\varepsilon_{i}^{p}$ 
Table 2

Quintile count regression for factors influencing CD4 cell count in newly diagnosed HIV-infected people in Iran (1987-2016).

\begin{tabular}{|c|c|c|c|c|c|c|}
\hline \multirow[t]{3}{*}{ Variable } & \multicolumn{6}{|c|}{ CD4 count at diagnosis } \\
\hline & \multicolumn{2}{|l|}{ 1st Quintile } & \multicolumn{2}{|l|}{ Median } & \multicolumn{2}{|l|}{ 3rd Quintile } \\
\hline & Coefficient & P-value & Coefficient & P-value & Coefficient & P-value \\
\hline Intercept & 6.780 & $<0.001$ & 6.99 & $<0.001$ & 7.219 & $<0.001$ \\
\hline \multicolumn{7}{|l|}{ Age } \\
\hline$<30$ & Reference & & & & & \\
\hline $30-40$ & -0.343 & 0.041 & -0.25 & 0.127 & -0.214 & 0.017 \\
\hline $40-50$ & -0.497 & 0.012 & -0.37 & 0.031 & -0.316 & 0.043 \\
\hline$>50$ & -0.487 & 0.095 & -0.53 & $<0.001$ & -0.336 & $<0.001$ \\
\hline \multicolumn{7}{|l|}{ Sex } \\
\hline Female & Reference & & & & & \\
\hline Male & -0.203 & 0.077 & -0.11 & 0.422 & -0.084 & 0.472 \\
\hline \multicolumn{7}{|l|}{ Marital Status } \\
\hline Single & Reference & & & & & \\
\hline Married & 0.048 & 0.765 & -0.009 & 0.969 & -0.041 & 0.675 \\
\hline Widow and Divorce & -0.077 & 0.698 & -0.002 & 0.993 & 0.031 & 0.831 \\
\hline Unknown & -0.302 & 0.349 & -0.125 & 0.668 & -0.078 & 0.356 \\
\hline \multicolumn{7}{|l|}{ Education } \\
\hline Illiterate & Reference & & & & & \\
\hline Primary School & 0.008 & 0.962 & -0.011 & 0.935 & 0.018 & 0.848 \\
\hline Secondary School & 0.153 & 0.366 & 0.008 & 0.934 & 0.029 & 0.811 \\
\hline High School & 0.083 & 0.744 & -0.004 & 0.976 & 0.034 & 0.454 \\
\hline Academic & 0.089 & 0.696 & -0.052 & 0.734 & -0.038 & 0.752 \\
\hline Unknown & -0.141 & 0.612 & -0.094 & 0.462 & -0.011 & 0.951 \\
\hline \multicolumn{7}{|l|}{ Job } \\
\hline Employed & Reference & & & & & \\
\hline Unemployed & -0.005 & 0.966 & -0.012 & 0.963 & 0.017 & 0.864 \\
\hline Unknown & -0.090 & 0.645 & -0.018 & 0.885 & -0.006 & 0.950 \\
\hline \multicolumn{7}{|l|}{ Transmission } \\
\hline Mother to child & Reference & & & & & \\
\hline Injecting drug users & -0.390 & 0.121 & -0.392 & 0.194 & -0.406 & 0.035 \\
\hline Unsafe sexual & -0.333 & 0.139 & -0.318 & 0.038 & -0.371 & 0.040 \\
\hline Blood transfusion \&Unknown & -0.575 & 0.115 & -0.456 & 0.013 & -0.500 & 0.001 \\
\hline \multicolumn{7}{|l|}{ WHO Clinical Stage } \\
\hline Stage 1 & Reference & & & & & \\
\hline Stage 2 & -0.492 & 0.019 & -0.370 & 0.028 & -0.216 & 0.168 \\
\hline Stage 3 & -1.425 & $<0.001$ & -1.118 & 0.001 & -0.806 & $<0.001$ \\
\hline Stage 4 & -1.756 & $<0.001$ & -1.377 & $<0.001$ & -1.048 & $<0.001$ \\
\hline Unknown & -0.599 & 0.003 & -0.224 & 0.056 & -0.085 & 0.599 \\
\hline \multicolumn{7}{|l|}{ Year of HIV Diagnosis } \\
\hline Before 2006 & Reference & & & & & \\
\hline 2006-2011 & -0.722 & $<0.001$ & -0.477 & 0.052 & -0.359 & 0.051 \\
\hline After 2011 & -0.728 & $<0.001$ & -0.418 & 0.077 & -0.306 & 0.050 \\
\hline \multicolumn{7}{|l|}{ TB co-infection } \\
\hline No & Reference & & & & & \\
\hline Yes & 0.204 & 0.122 & 0.187 & 0.561 & 0.160 & 0.419 \\
\hline
\end{tabular}

In which the value of $0<\mathrm{p}<1$ represents the contribution of the population below to the quantile p. For quantile regression models, the pth quantile is as follows: ${ }^{14}$

$Q^{p}\left(y_{i} \mid x_{i}\right)=\beta_{0}^{p}+\beta_{1}^{p} x_{i}$

This model is analogous to the OLS regression model, hence the estimation of the parameters is via the minimization procedure. For a random sample of $Y$ it is well known that the $\widehat{\beta_{1}^{p}}, \widehat{\beta_{0}^{p}}$ are estimated with the Least Absolute Deviations method that minimizes the following sum of the absolute deviations:

$p \sum_{y_{i} \geq \beta_{0}^{p}+\beta_{1}^{p} x_{i}}\left|y_{i}-\beta_{0}^{p}-\beta_{1}^{p} x_{i}\right|+(1-p) \sum_{y_{i}<\beta_{0}^{p}+\beta_{1}^{p} x_{i}}\left|y_{i}-\beta_{0}^{p}-\beta_{1}^{p} x_{i}\right|$

One problem with using quantile regression to count data is that the cumulative distribution function of the response parameter is not continuous, and so the quantiles are not continuous, so they can't be presented as a continuous function of the covariates. Adding uniform random noise (jittering) to the counts can overcome this problem. ${ }^{13}$

\section{Results}

Between 1987 and 2016, data on 4402 patients aged from 16 to 78- year-old, whose CD4 cells count were measured in the first three months later of diagnosis, as well as no missing information, was included in this study. The average age of study participants was $34.86 \pm 10.43$ SD (standard deviation) and 3030 (68.8\%) of them were males. Most of the participants 1740 (39.5\%) had an unemployed job status. Similarly, most participants had baseline WHO clinical stage I 1997 (45.4\%) and transmission way in $2104(47.8 \%)$ of patients was through injecting a drug. Other information about the variables associated with these patients is presented in Table 1.

The results of fitting the quantile count regression model are presented in Table 2. Also, results of the quantile regression analysis for every quantile as well as their $95 \% \mathrm{CI}$ are presented in Fig. 1. It is noted that for this plot the $\mathrm{x}$-axis represents quantiles of $\mathrm{CD} 4$ count, and the $\mathrm{y}$ axis represents the change in CD4 count associated with a one-unit change in the studied covariate, holding other covariates constant.

Male gender was negatively associated with CD4 count at diagnosis for all quantiles (25, 50, and 75). All the age group of the diagnosis has a significant effect for the third quantile, while for the first quantile, the age groups of 30-40 and 40-50 have been significant effect and for the second quantile, the age groups of $40-50$ and above 50 have been the significant effect the CD4 counts. For all age groups in all quantile, the CD4 counts decrease with increasing age group. Marital status, job employment, and education level have no significant effect on CD4 


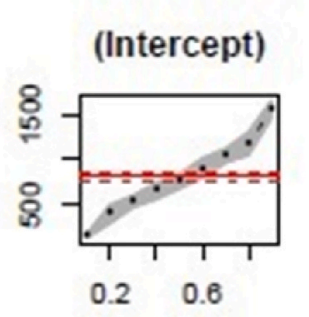

Married

(Single)

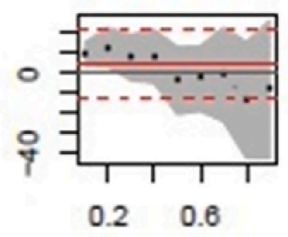

High School (Illiterate)

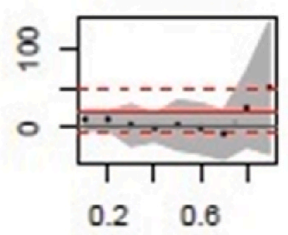

Inject Drug User (Mother to Child)

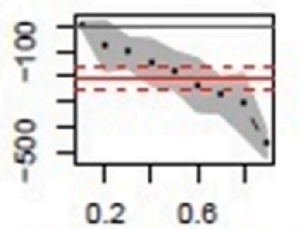

Clinical StageIV (StageI)

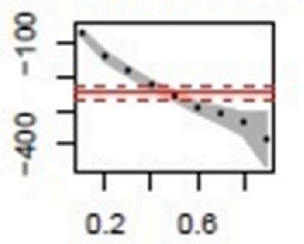

Male

(Female)

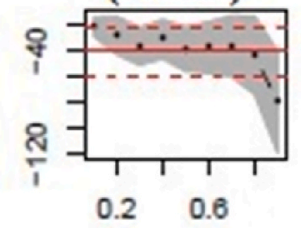

Divorce\&Widow

(Single)

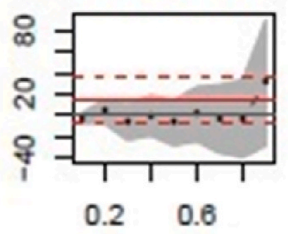

Academic (Illiterate)

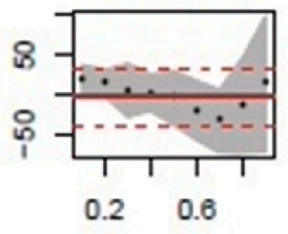

Unsafe Sex (Mother to Child)

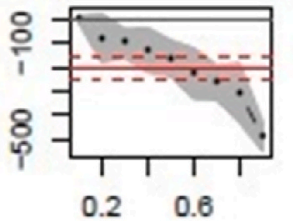

Age 30-40

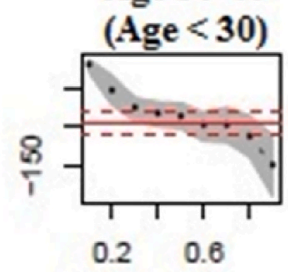

Unkhown

(Single)

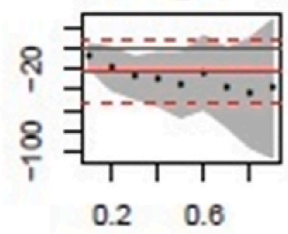

Unkhown (Illiterate)

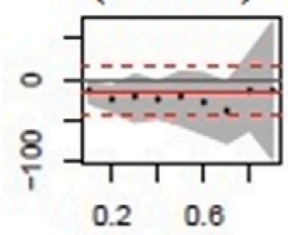

Unkhown (Mother to Child)

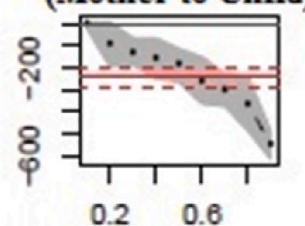

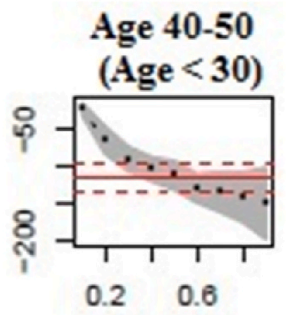

Primary School (Illiterate)

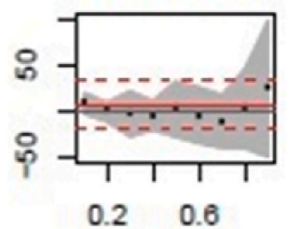

Employed (Unemployed)

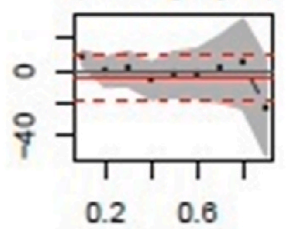

Clinical StageII (StageI)

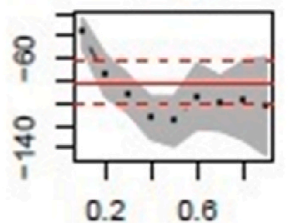

Age $>\mathbf{5 0}$

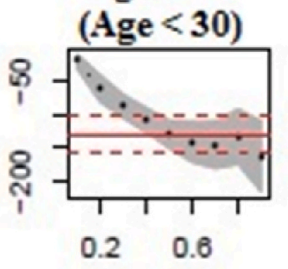

Secondary School (Illiterate)

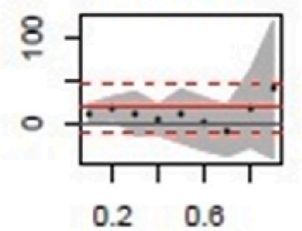

Unkhown

(Unemployed)

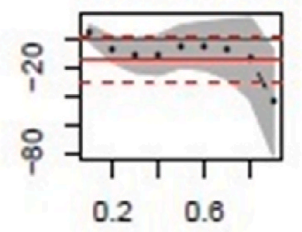

Clinical StageIII

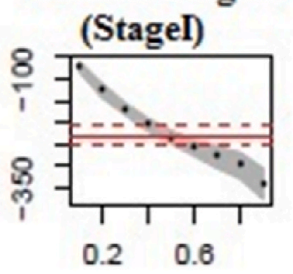

Clinical Stage Unkhown

Year Diag: 2006-11 Year Diag: After 2011
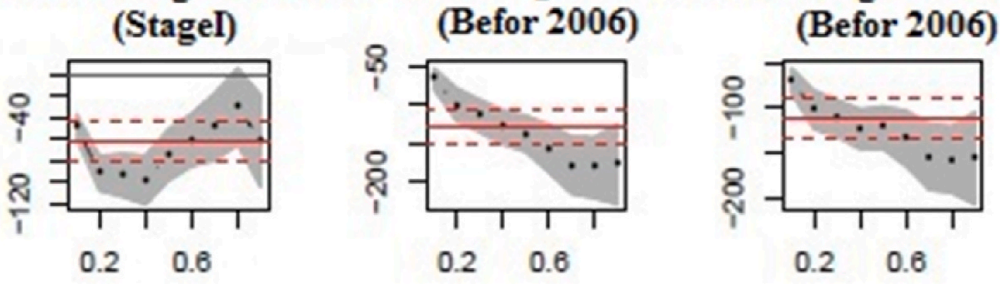

TB Co-infection

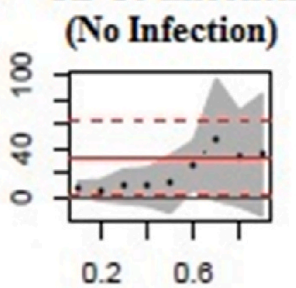

Fig. 1. Coefficients of quantile regression model for CD4 count for every quantiles as well as their $95 \%$ CI.

counts in different quantiles.

In the first quantile, the transmission way has no significant effect on the CD4 counts. However, in the second quantile patients infected by unsafe sex and blood transition had significantly lower CD4 counts than mother to child transition people. Also, in the third quantile drug user patients and people infected by unsafe sex and blood transition had significantly lower CD4 counts than mother to child transition people.

In the first quantile, all people with WHO Clinical Stage (II, III, IV, and unknown) had significantly lower CD4 counts than the people with WHO Clinical Stage I. For the third quantile, only people with WHO Clinical Stage III and IV had significantly lower CD4 counts than the people with WHO Clinical Stage I.

Year of HIV diagnosis had a significant effect on the CD4 counts for the first quantile. Also, TB co-infection had no significant effect on CD4 counts for all quantiles.

\section{Discussion}

In this study, the quantile regression model was used to account for potential heterogeneity in the association of various explanatory variables across different quantiles of CD4 counts at the time of diagnosis in HIV patients. Traditional regression models such as the log-linear model assume that the impact of the independent variables is the same at different quintiles of the CD4 distribution. Therefore based on these models the picture of the relationship is incomplete. Quantile regression provides a more accurate description of the conditional variable distribution and its determinants. Most statistical models that describe the relationship between $\mathrm{CD} 4$ cell counts and the factors that affect them use 
models with count data and their variants to investigate the average effects of covariates on cell counts. 3, 5, 9-10 While using quantile regression for counts as a methodological alternative in analyzing CD4 counts allows various quantiles of a population to be estimated. Some factors that may be poorly related to average CD4 cell counts may be strongly related to lower cell counts. Insight regarding such differential associations is therefore essential for identifying populations at risk based on different levels of cell counts in the diagnosis of HIV. ${ }^{8}$ To achieve this goal, compared to standard regression models, the use of modern statistical methods such as quantile regression can allow a more comprehensive analysis of the factors associated with CD4 cell counting. Using this model can also quantify the relative loss of cells related to a specific risk factor. ${ }^{8}$

On the other hand, the assumption of the equality of mean and variance of the response distribution (over dispersion) in the log-linear model restricts their use in real. ${ }^{12}$ Considering that the quantile regression model for count data has a separate scale parameter and over dispersion does not occur, the problem of over dispersion has been solved for this model.

Quantile regression was introduced in 1978 by Quincker and Bast, whose purpose is to model conditional quantiles as a function of predictors. ${ }^{13}$ Tang et al., in 2014, used a logistic regression method to identify the factors associated with baseline CD4 cell count (within 6 months of diagnosis). The variables studied in the Tong study include the year of diagnosis of HIV, age, gender, race, marital status, employment status, educational level, and the way of transmission of the virus. The results of the study indicate that older patients are more likely to be diagnosed late in the disease. Also, due to the use of preventive prophylaxis in China over the period from 2006 to 2012, the percentage of patients with a late diagnosis was declining. According to the authors, one of the limitations mentioned for their study is the use of local data and the non-use of country data. Also, in this study, the staging factor of the disease has not been investigated. ${ }^{9}$ Meier et al. (2007) used a multivariate regression method to identify factors affecting CD4 cell count in Senegalese patients infected with other infections (other than HIV). Also, separate models for men and women have been fitted in this study. The results indicate that the average CD4 count in men is significantly lower than that of women. Smoking also has an important impact on the number of CD4 cells. ${ }^{3}$ In the year 2016, Bruneau et al., employed multiple quantile regression methods to identify the factors affecting the number of CD4 cells in AIDS patients in France. The purpose of this study was to identify important factors on various levels of CD4 at the time of diagnosis of AIDS. The results of this study showed that in all studied cases, higher age, male status, external migrant patients, association with hepatitis $\mathrm{B}$ and $\mathrm{C}$ viruses, rural residency and homosexual transmission method have a negative association with CD4 cell count. However, the statistical significance of these factors varied in different quantile. Foreign migrant patients are the only variables that were significant in all of the quantiles. ${ }^{8}$ In 2016, Abbas Tabar et al., used a Poisson regression model to determine the factors affecting the CD4 count in AIDS patients in Shiraz. The results of this study showed that female gender, unemployment, addiction, injection from a common syringe, sexually transmitted infections, longer illness time and age had a negative effect on the $\mathrm{CD} 4$ count, while factors such as being present Health insurance, receiving HAART treatment and higher initial CD4 count have a positive effect on CD4 count. One of the weaknesses of this study is the lack of an examination of the appropriateness of fitting the model used for data. ${ }^{10}$

\section{Conclusion}

The study findings indicated that variables, such as older age, clinical stage, transmission way, and year of HIV diagnosis could play the role of risk factors for $\mathrm{CD} 4$ counts at the time of diagnosis in HIV patients. However, the relationship between different variables was not uniform distributed in many different quantiles. The late detection of HIV and the lack of awareness of people about their HIV status delay in receiving disinfection therapies, thereby reducing their life expectancy and transmission of HIV by these people. The results of this study can be particularly useful for the prevention, management and clinical care of people with HIV.

\section{Ethics approval and consent to participate}

This study was approved by the Ethics Committee of Hamadan University of Medical Sciences with IR.UMSHA.REC.1398.406.

\section{Declaration of competing interest}

There are no conflicts of interest.

\section{Acknowledgements}

The authors would like to express their gratitude to Vice Chancellor of Research of Hamadan University of Medical Sciences for financial support (grant No. 9806264725).

\section{References}

1 Grover G, Vajala R, Swain PK. On the assessment of various factors effecting the improvement in CD4 count of aids patients undergoing antiretroviral therapy using generalized Poisson regression. J Appl Stat. 2015;42(6):1291-1305.

2 Temesgen A. Application of Poisson mixed combined models for identifying correlations of CD4 count progression in HIV infected TB patients during ART treatment period. Int J Stat Probab. 2017;6(5):42-52.

3 Mair C, Hawes SE, Agne HD, et al. Factors associated with CD4 lymphocyte counts in HIV-negative Senegalese individuals. Clin Exp Immunol. 2008;151(3):432-440.

4 Akinbami AA, Gbadegesin A, Ajibola SO, et al. Factors influencing CD4 cell count in HIV-positive pregnant women in a secondary health center in Lagos, Nigeria. HIV AIDS. Auckl). 2015;7:115-118.

5 Seyoum A, Ndlovu P, Zewotir T. Quasi-Poisson versus negative binomial regression models in identifying factors affecting initial CD4 cell count change due to antiretroviral therapy administered to HIV-positive adults in North-West Ethiopia (Amhara region). AIDS Res Ther. 2016;13:36.

6 Montarroyos UR, Miranda-Filho DB, César CC, et al. Factors related to changes in CD4+ T-cell counts over time in patients living with HIV/AIDS: a multilevel analysis. PloS One. 2014;9(2). e84276-e.

7 Langford SE, Ananworanich J, Cooper DA. Predictors of disease progression in HIV infection: a review. AIDS Res Ther. 2007;4.

8 Bruneau L, Billaud E, Raffi F, Hanf M. Factors associated with the level of CD4 cell counts at HIV diagnosis in a French cohort: a quantile regression approach. Int J STD AIDS. 2017;28(4):397-403.

9 Tang H, Mao Y, Shi CX, et al. Baseline CD4 cell counts of newly diagnosed HIV cases in China: 2006-2012. PloS One. 2014;9(6). e96098-e.

10 Abbastabar H, Rezaianzadeh A, Rajaeefard A, Ghaem H, Motamedifar M, Afsar Kazeroon P. Determining factors of cd4 cell count in hiv patients: in a historical cohort study. Int J Life Sci Pharma Res. 2016;(Issue 1):93-101. SP 2016.

11 Mirzaei M, Farhadian M, Poorolajal J, Kazerooni P, Tayeri K, Mohammadi Y. Survival rate and the determinants of progression from HIV to AIDS and from AIDS to the death in Iran: 1987 to 2016. Asian Pac J Trop Med. 2019;12(2):72-78.

12 Kutner MH, Nachtsheim CJ, Neter J, Li W. Applied Linear Statistical Models. McGrawHill Irwin Boston; 2005.

13 Koenker R, Bassett Jr G. Regression quantiles. Econometrica: J Econ Soc. 1978:33-50.

14 Buchinsky M. Recent advances in quantile regression models: a practical guideline for empirical research. J Hum Resour. 1998:88-126. 